\title{
Efeito dos extratos aquoso e oleoso de Nim [Azadirachta indica A. Juss (Meliaceae)] na produção de patulina em maçãs contaminadas por Penicillium expansum
}

\author{
Effect of aqueous and oily extracts of Neem [Azadirachta indica A. Juss (Meliaceae)] on patulin production in \\ apples contaminated with Penicillium expansum
}

\author{
Carla Cristina Arroteia ${ }^{\mathrm{I}}$ Carlos Kemmelmeier ${ }^{\mathrm{I} *}$ Miguel Machinski Junior ${ }^{\mathrm{II}}$
}

\section{RESUMO}

A Região Sul do Brasil é grande produtora de maçã, sendo $80 \%$ destinada ao consumo in natura. As micotoxinas são metabólitos secundários de fungos presentes na cadeia alimentar como contaminantes, causando diversos efeitos toxicológicos e imunológicos. Considerando que a patulina seja uma micotoxina produzida por Penicillium expansum, principal contaminante da maçã propôs-se investigar a ação de extratos aquoso e oleoso de Nim (Azadirachta indica) em maçã artificialmente contaminada. Foram testados dois tipos de extratos: o extrato aquoso obtido de maceração de folhas de Nim nas concentrações de 5, 10, 20 e 30\%, e o extrato oleoso comercial (DalNeem ${ }^{\circledR}$ ), obtido de sementes de Nim, nas concentrações de 0,125, 0,25, 0,5, 1, 2 e 5\%. Os extratos aquosos não alteram a produção da patulina em maçãs contaminadas artificialmente por P. expansum, mas o extrato oleoso obtido das sementes da planta diminuiu acentuadamente a produção de patulina, inclusive em concentrações inferiores a 0,5\%.

Palavras-chave: Azadirachta indica, maçã, Nim, patulina, Penicillium expansum.

\section{ABSTRACT}

The South region of Brazil is a major apple producer, where $80 \%$ is destined to the "in natura" consumption. The mycotoxins are fungal secondary metabolites present as contaminants in the food chain, causing several toxicological and immunological effect. Patulin is a mycotoxin mainly produced by Penicillium expansum and well known as the main contaminant in apples. Due to this contamination, the aim of this work was to access the effect of Neem extract (Azadirachta indica) on artificially contaminated apples. Two types of Neem extracts were tested: the aqueous extracts of Neem leafs at 5, 10, 20 and 30\% concentrations, and commercial seed oil of Neem (DalNeem $\left.{ }^{\circledR}\right)$ at 0.125, 0.25, 0.5, 1,2 and $5 \%$ in water. Although the addition of Neem aqueous extracts in artificially contaminated apples with $\boldsymbol{P}$. expansum was unable to affect the patulin production, the Neem seed oil extract at concentrations as lower as $0.5 \%$, caused a pronounced diminution over patulin production.

Key words: Apple, Azadirachta indica, Neem, patulin, Penicillium expansum.

\section{INTRODUÇÃO}

A maçã é uma das culturas frutícolas mais importantes no âmbito mundial, só superada em volume pela cultura de videira e cítricos. O consumo de maçã in natura ou processada é amplamente difundido, sendo seus produtos derivados: suco, polpa, purê, produtos fermentados e desidratados, conservas e doces (MACHUCA, 1988). Mesmo com o crescimento da industrialização deste fruto observado na última década (cerca de 5\% somente na safra 2004) parte expressiva da produção nacional, $80 \%$ do total, ainda é destinada ao consumo in natura (EPAGRI/CEPA, 2005).

As micotoxinas, responsáveis por diversos efeitos tóxicos e imunológicos, atingem a cadeia alimentar por contaminação agrícola, produtos animais ou a partir de derivados dessas fontes (SINHA \& BHATNAGAR, 1998).

'Departamento de Bioquímica, Universidade Estadual de Maringá (UEM), 87020-900, Maringá, PR, Brasil. E-mail: ckemmelmeier@uem.br.*Autor para correspondência.

"Departamento de Análises Clinicas, UEM, Maringá, PR, Brasil. 
Fungos toxigênicos do gênero Penicillium freqüentemente contaminam alimentos e produtos agrícolas, sendo que Penicillium expansum, psicrotrófico, ataca principalmente a maçã, produzindo a micotoxina patulina (HARISSON, 1989; HOPKINS, 1993; BROWN et al., 1996; PITT \& HOCKING, 1997).

A patulina $\{4-$ hidroxi $-4 \mathrm{H}-$ furo $[3,2-\mathrm{c}]$ pirano - $2(6 \mathrm{H})$ - ona $\}$ em maçãs e derivados vem sendo motivo de constantes investigações, com relatos atingindo níveis de até $45 \mathrm{mg} / \mathrm{L}$ (LINDROTH \& NISKANEM, 1978; HARISSON, 1989; TANIWAKI et al., 1989; MACHINSKI JR \& MÍDIO, 1995). A

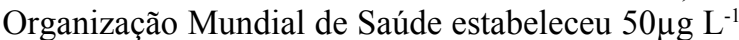
como limite máximo de patulina para o suco de maçã (PRIETA et al., 1992; KUBACHI, 1986).

Compostos químicos sintéticos têm sido o principal meio de controle de pragas. Apesar de sua contribuição para a produção agrícola, seu uso intensivo e indiscriminado favoreceu o surgimento de pragas secundárias, sem se conseguir eliminar os problemas já existentes. Além disso, são altamente tóxicos e prejudiciais ao ambiente e à saúde humana (MARQUES et al., 2004). Compostos de origem vegetal podem se constituir em importantes agentes de controle, pela fácil obtenção e utilização, pelo baixo custo e por minimizarem os problemas apresentados pelos produtos químicos sintéticos. Extratos biologicamente ativos obtidos de folhas, frutos, sementes e do tronco de Nim (Azadirachta indica A. Juss.) são reconhecidos pelas múltiplas propriedades terapêuticas, inseticidas, nematicidas e fungicidas (MOSSINI \& KEMMELMEIER, 2005), sendo a azadiractina considerada o composto ativo mais potente da árvore de Nim (BUTTERWORTH \& MORGAN, 1968).

Estudos recentes confirmaram o uso do extrato de Nim na inibição da produção da aflatoxina (ALLAMEH et al., 2002; RAZZAGHI-ABYANEH et al., 2005). MOSSINI et al. (2004) demonstraram o efeito inibitório do extrato aquoso das folhas de Nim sobre a produção de patulina in vitro, embora sem inibir o crescimento vegetativo do fungo. No presente estudo, analisou-se o efeito inibitório do extrato aquoso e oleoso de Nim em maçãs artificialmente inoculadas com $\boldsymbol{P}$. expansum produtor de patulina.

\section{MATERIAL E MÉTODOS}

Foi utilizado Penicillium expansum isolado no 16 , obtido de maçãs deterioradas e produtor de patulina (TEIXEIRA et al., 1998), que está preservado em sílica (SMITH \& ONIONS, 1983) no Laboratório de Química e Fisiologia de Microorganismos do Departamento de Bioquímica da Universidade Estadual de Maringá.
Folhas de Azadirachta indica A. Juss (Meliaceae) do IAPAR (Instituto Agronômico do Paraná - Londrina, PR) foram secadas e transformadas em pó, para preparar o extrato aquoso de folhas de Nim em concentrações de 5, 10, 20 e 30\%. Para extração, o pó foi submetido à agitação em água destilada durante doze horas e ao abrigo da luz, filtrado em gaze e conservado a $4^{\circ} \mathrm{C}$. Paralelamente, utilizou-se o produto comercial (marca DalNeem ${ }^{\circledR}$ ) de óleo extraído das sementes de Nim, adquirido no mercado local e diluído nas concentrações finais de $0,125,0,25,0,5,1,2$ e $5 \%$ em água destilada.

Maçãs da cultivar "Fuji" foram adquiridas aleatoriamente no mercado local e utilizadas como substrato para o crescimento do fungo. As maçãs foram descontaminadas, por imersão em solução de hipoclorito de sódio:água (1:3), durante 90 segundos, lavadas em água destilada e secadas (ROSS, 1995).

Para obtenção do inóculo fúngico (104 e 108 conídios), uma partícula de sílica com fungo preservado (SMITH \& ONIONS, 1983) foi rolada em placa de Petri contendo BDA (batata dextrose ágar) e cultivada a $25^{\circ} \mathrm{C}$ por uma semana. Os conídios resultantes do crescimento fúngico foram raspados e suspensos em $10 \mathrm{~mL}$ de solução Tween 80 a $0,1 \%$ (esterilizada a $121^{\circ} \mathrm{C}$ por 15 minutos) e homogeneizados para contagem em Câmara de Neubauer.

Para contaminar as maçãs, dois tipos de procedimentos foram testados. No primeiro, maçãs tratadas com hipoclorito foram inoculadas com 108 conídios de $\boldsymbol{P}$. expansum isolado 16, introduzidos superficialmente na casca (periderme) lesionada da maçã. Os experimentos se constituíram em quadruplicata para cada concentração do extrato de Nim e para os controles positivos $(\mathrm{C}+$ : maçãs inoculadas com $\boldsymbol{P}$. expansum) e controles negativos (C-: maçãs sem inoculação de $\boldsymbol{P}$. expansum). Em seguida, os frutos foram pulverizados com o extrato aquoso de Nim (nas concentrações de 5, 10, 20 e 30\%) e incubados por 30 dias a $25^{\circ} \mathrm{C}$, condições ideais para a produção de patulina descritas por ROSS (1995). No segundo procedimento de contaminação das maçãs, também realizado em quadruplicata, três cortes cruzados foram assepticamente feitos na parte superior dos frutos (ROSS, 1995). Com uma seringa descartável estéril de $1 \mathrm{~mL}$, introduziu-se nos cortes o volume de inóculo correspondente a 104 conídios na polpa das frutas (ROSS, 1995). A seguir, as frutas foram pulverizadas com o extrato aquoso (concentrações de 5, 10, 20 e $30 \%$ ) ou oleoso de Nim (concentrações de $0,125,0,25$, $0,5,1,2$ e $5 \%$ em água), incubadas a $25^{\circ} \mathrm{C}$ por 30 dias, procedendo-se à extração e detecção de patulina. 
Para a extração, as maçãs foram trituradas em liquidificador e filtradas sob vácuo, sendo $25 \mathrm{~mL}$ de suco particionados três vezes em funil de separação, com igual volume de acetato de etila. Os extratos, correspondentes à fase superior (orgânica) do processo de partição, foram combinados em frasco tipo becker e tratados com $10 \mathrm{~g}$ de sulfato de sódio anidro, evaporados a $40^{\circ} \mathrm{C}$, em evaporador rotatório, até um volume inferior a $25 \mathrm{~mL}$, e completados para $100 \mathrm{~mL}$ com benzeno. Para se proceder a clarificação dos extratos foram usadas colunas $(500 \mathrm{~mm} \times 10 \mathrm{~mm}, 25 \mathrm{~mL})$, empacotadas com 8,0g de sílica gel 60 G, 0.063-0.2 mesh (Merck), previamente suspensas em benzeno (MACHINSKI, 1994). Os extratos introduzidos foram eluídos com $100 \mathrm{~mL}$ de benzeno-acetato de etila na proporção de 75:25 v/v, e os eluatos foram secados em evaporador rotatório, redissolvidos com $2 \mathrm{~mL}$ de acetato de etila e submetidos à cromatografia de camada delgada (CCD) e à cromatografia líquida de alta eficiência(CLAE) (ROSS, 1995).

Patulina foi detectada conforme o método descrito por SCOTT \& KENNEDY (1973). O padrão de patulina $\left(\mathrm{ACROS}^{\circledR}\right.$ ) foi preparado em acetato de etila na concentração de $1 \mathrm{mg} / \mathrm{mL}$ e armazenado a $4^{\circ} \mathrm{C}$. Para $\mathrm{CCD}$, volumes de $10 \mu \mathrm{L}$ do padrão de Patulina, amostras, controles e extratos (aquoso ou oleoso) foram aplicados em placas de sílica com e sem indicador de fluorescência (Cromatofolha AL TLC 20 x 20cm Silicagel 60 e Silicagel $F_{254}-$ Merck $^{\circledR}$ ) e desenvolvidas em clorofórmio - acetona $(9: 1, \mathrm{v} / \mathrm{v})$. As placas com indicador de fluorescência foram expostas à luz ultravioleta de comprimento de onda curto $(254 \mathrm{~nm})$, enquanto que as placas sem indicador de fluorescência foram reveladas com solução de cloridrato de metilbenzotiazolinonaidrazona (MBTH) $0,5 \%$ em $5 \%$ de ácido fórmico e aquecidas a $130^{\circ} \mathrm{C}$, por $15 \mathrm{~min}$ (MACHINSKI, 1994). A patulina apresentou-se como uma mancha marrom-amarelada fluorescente sob luz ultravioleta em comprimento de onda longo ( $365 \mathrm{~nm}$ ).

Para a análise em CLAE, os extratos filtrados em membranas de $0,45 \mu \mathrm{m}$ foram injetados $(20 \mu \mathrm{l})$ no Cromatógrafo Líquido Shimadzu, ${ }^{\circledR}$ equipado com uma bomba LC-10AD, um injetor Rheodine ${ }^{\circledR}$, um detector UV SPD-10A, um módulo de comunicação CBM-101 Communications Bus Module e um sistema de trabalho Class-CR10 Workstation system, empregando coluna cromatográfica Shimpack ${ }^{\circledR}$ GLC-ODS $(150$ x 4,6mm, $5 \mu \mathrm{m})$. A fase móvel foi metanol-água $(70: 30 \mathrm{v} / \mathrm{v}) \mathrm{com}$ fluxo de $0,5 \mathrm{~mL} \mathrm{~min}^{-1}$ para uma corrida isocrática de 10 min. A absorbância das amostras e do padrão de patulina foi detectada a $275 \mathrm{~nm}$, e o tempo de retenção e a área de cada pico foram calculados pelo programa Class-CR10 software.

\section{RESULTADOS E DISCUSSÃO}

As análises por CCD dos extratos das maçãs inoculadas com 108 conídios introduzidos na superfície da casca (periderme) lesionada da maçã, seguidas de pulverização com extrato aquoso de Nim, não indicaram a inibição da produção de patulina por $\boldsymbol{P}$. expansum (Resultados não apresentados). O segundo experimento com inoculação de $\boldsymbol{P}$. expansum por corte, tratado com extrato aquoso de folhas secas de Nim, também não apresentou efeito inibidor na produção de patulina (Figura 1). Esses resultados negativos obtidos na fruta in natura por pulverização do extrato, contrapõem-se aos resultados obtidos por MOSSINI et al. (2004) em culturas líquidas, in vitro.

Em vista disto, procedeu-se ao ensaio com extrato oleoso, considerando que os compostos bioativos do Nim têm sido detectados em todas as partes da planta, principalmente nas sementes (MOSSINI \& KEMMELMEIER, 2005). De acordo com as instruções do fabricante, o extrato de óleo de Nim $\left(\right.$ DalNeem $\left.^{\circledR}\right)$ deve ser emulsionado com água na concentração de $0,5 \%$ e pulverizado. No presente trabalho, utilizaram-se concentrações entre 0,125 a 5\% do extrato oleoso de sementes de Nim. Em concentrações abaixo de $0,5 \%$, conforme analisado por CCD e CLAE (Figuras 2 e 3), o extrato oleoso de Nim inibiu a produção de patulina por $\boldsymbol{P}$. expansum. Nas concentrações acima de $0,5 \%$, não se observou efetiva inibição na produção de micotoxina, provavelmente devido à diminuição da solubilidade do extrato oleoso em água. As concentrações menores foram mais efetivas na inibição, indicando que provavelmente ocorreu um maior contato e absorção do extrato pelo fungo e substrato (maçã). A figura 4 mostra o aspecto das maçãs tratadas, onde se visualiza uma diminuição da contaminação fúngica em maçãs tratadas com concentrações abaixo de $0,5 \%$ do extrato oleoso de Nim. Entretanto, aparentemente, concentrações mais elevadas do extrato oleoso de Nim favoreceram o crescimento fúngico.

\section{CONCLUSÃO}

O óleo de Nim nas concentrações inferiores a $0,5 \%$ diminuiu acentuadamente a produção de patulina por P. expansum, indicando que a lipossolubilidade é essencial na sua atividade.

\section{AGRADECIMENTOS}

Ao programa de Pós-graduação em Ciências da Saúde da Universidade Estadual de Maringá (UEM).

Ciência Rural, v.37, n.6, nov-dez, 2007. 


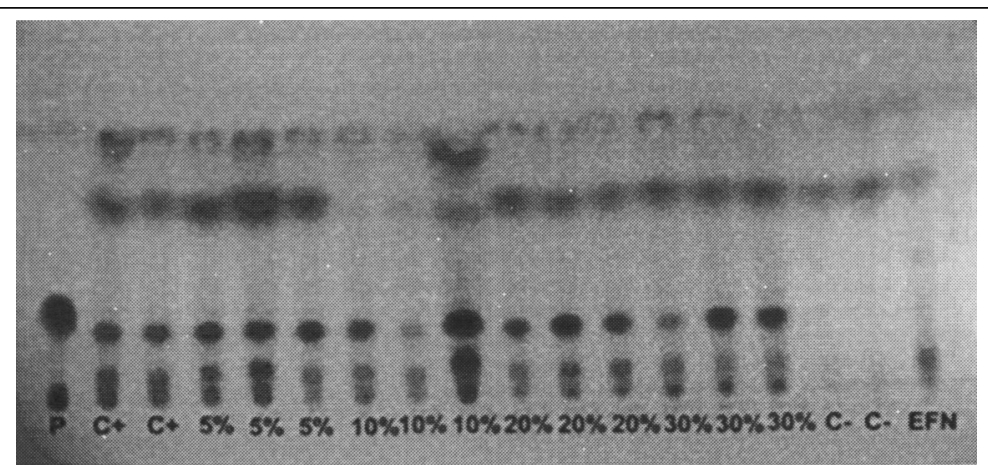

Figura 1 - Efeito do extrato aquoso da folha de Nim em maçã inoculada com $\boldsymbol{P}$. expansum (CCD 254nm): (P) Patulina; (C+) Controle positivo, maçãs inoculadas com P. expansum; Concentrações do extrato aquoso de Nim entre 5 e 30\%; (C-) Controle negativo, maçãs sem tratamento; (EFN) extrato aquoso, folhas de Nim.

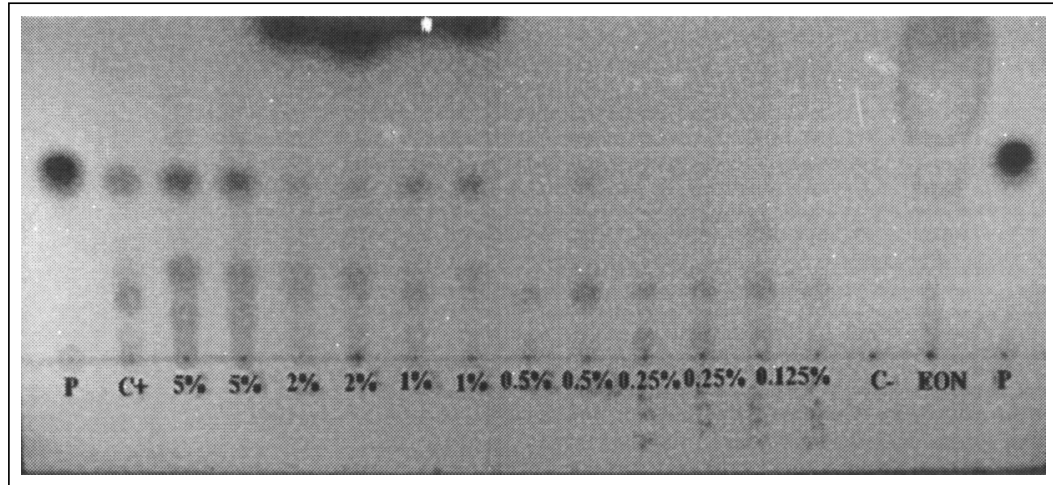

Figura 2 - Efeito do extrato oleoso das sementes de Nim em maçã inoculada com $\boldsymbol{P}$. expansum (CCD 254nm): (P) Patulina; $(\mathrm{C}+$ ) Controle positivo, maçãs inoculadas com P. expansum; concentrações do extrato oleoso de Nim entre 0,125 a 5\%; (C-) Controle negativo, maçãs sem tratamento; (EON) Extrato oleoso de Nim.

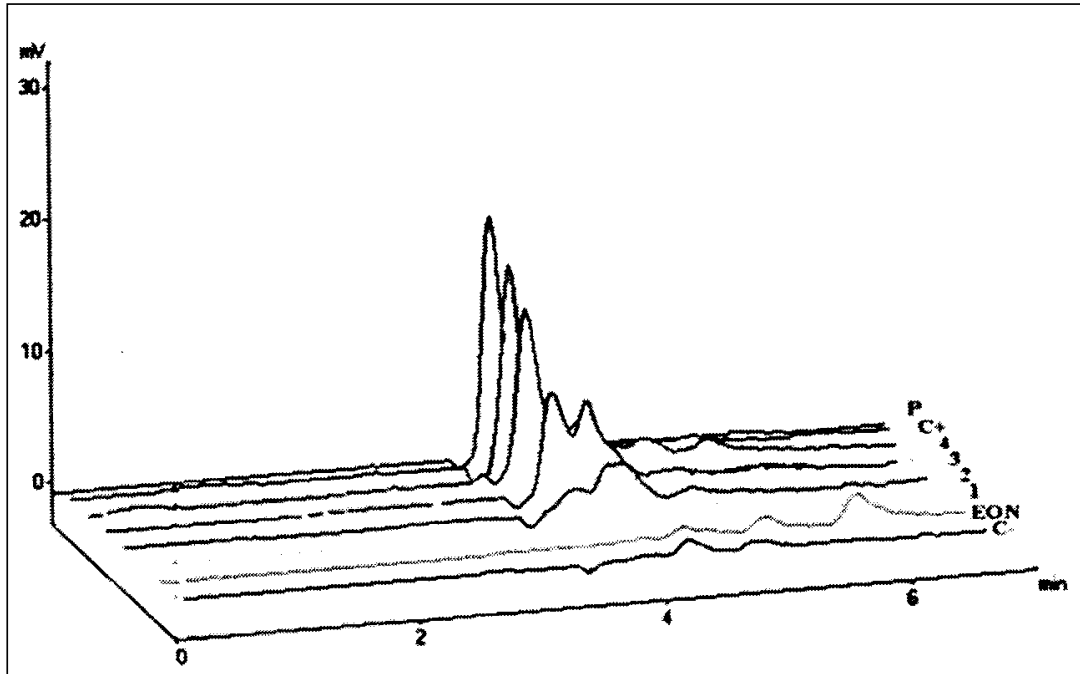

Figura 3 - Cromatograma: (P) Patulina; $(\mathrm{C}+)$ Controle positivo, maçãs inoculadas com $\boldsymbol{P}$ expansum; ( 1 a 4) Maçãs inoculadas com $\boldsymbol{P}$. expansum e tratadas com óleo de Nim, 0,125, 0,25, 0,5 e 1\%; (EON) Extrato oleoso de Nim; (C-) Controle negativo, maçãs sem tratamento. 


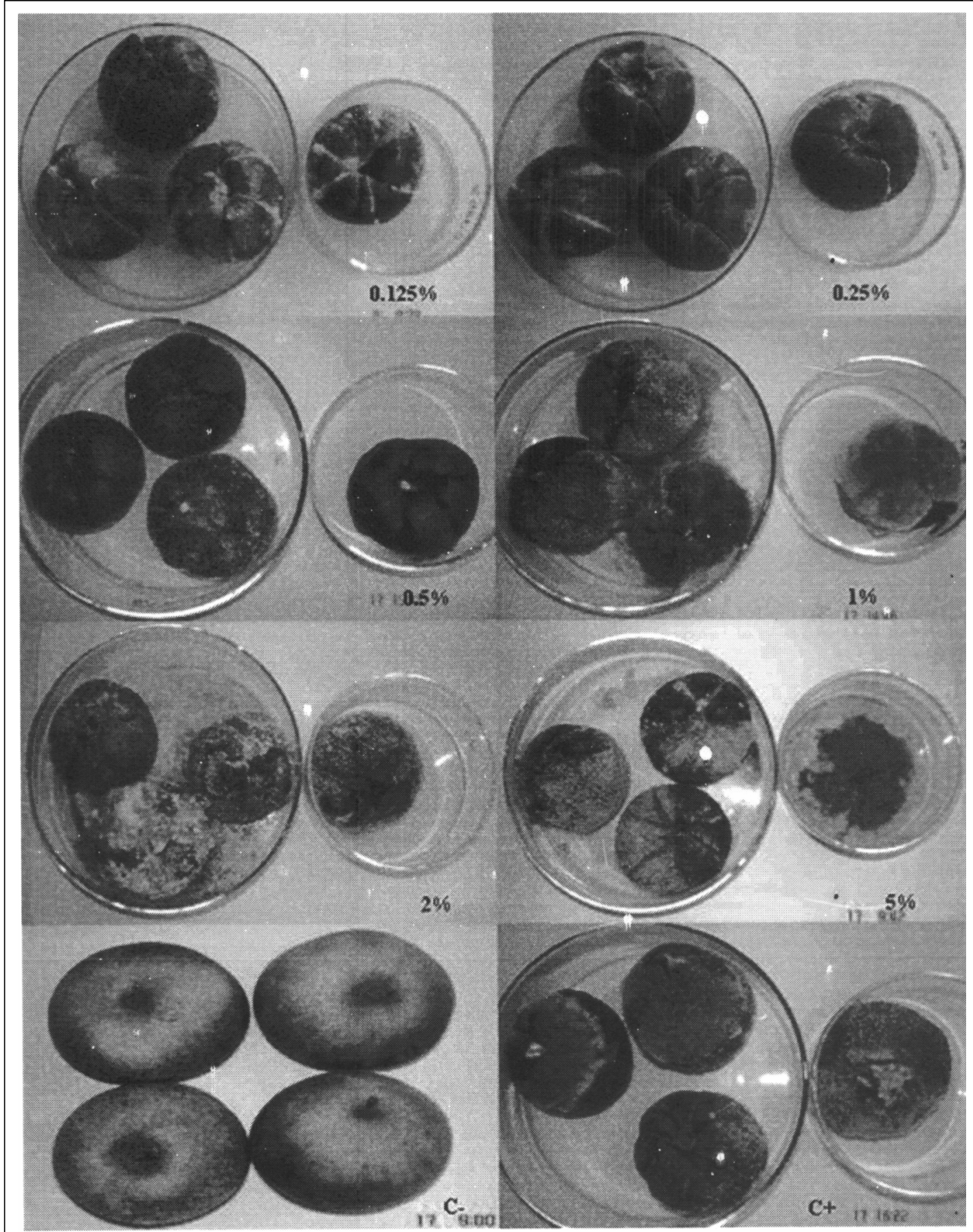

Figura 4 - Aspecto geral das maçãs utilizadas no procedimento. Maçãs inoculadas com $\boldsymbol{P}$. expansum e tratadas com extrato oleoso de Nim nas concentrações entre $0,125 \%$ e $5 \%$; (C-) Controle negativo com maçãs sem nenhum tratamento; $(\mathrm{C}+)$ Controle positivo com maçãs inoculadas com $\boldsymbol{P}$. expansum produtor de patulina.

\section{REFERÊNCIAS}

ALLAMEH, A. et al. Effects of neem leaf extract on production of aflatoxins and activities of fatty acid synthetase, isocitrate dehydrogenase and glutathione S-transferase in Aspergillus parasiticus. Mycopathologia, Dordrecht, v.154, p.79-84, 2002.
BROWN, N.L. et al. Patulin in apples: influence of deck storage and initial processing. Rome, Italy: IUPAC, 1996. p. 189 .

BUTTERWORTH, J.H.; MORGAN, E.D. Isolation of a substance that supresses feeding in locusts. Journal of the Chemical Society, London, v.35, n.1, p.23-24, 1968. 
EPAGRI/CEPA - Centro de Estudos de Safras e Mercados. Capturado em fev. de 2005. On line. Disponível na internet http:// www.icepa.com.br.

HARISSON, M.A. Presence and stability of Patulin in apples products: a review. Journal of Food Safety, Tumbull, v.9, p.147-153, 1989.

HOPKINS, J. The toxicological harzards of patulin. Food Chemical Toxicological, Oxford, v.31, n.6, p.455-459, 1993.

KUBACHI, S.J. The analysis and occurrence of patulin in apple juice in bioactive molecules. In: STEIN, P.S.; VLEGGAR, R. Mycotoxins and Phycotoxins. New York: Elsevier, 1986. p. 293-304.

LINDROTH, S.; NISKANEM, A. Comparision of potentia patulin hazard in home made and commercial apple products. Journal of Food Science, Chicago, v.43, p.446-448, 1978.

MACHINSKI JR., M. Métodos analíticos para a determinação de patulina em suco de maçã. 1994. $132 \mathrm{f}$. Dissertação (Mestrado em análises toxicológicas) - Curso de Pós-graduação em farmácia, Universidade de São Paulo.

MACHINSKI JR., M.; MÍDIO, A.F. Patulina em alimentos aspectos toxicológicos e analíticos. Revista de Farmácia e Bioquímica da Universidade de São Paulo, São Paulo, v.31, n.1, p.1-19, 1995.

MACHUCA, M.N. Aspectos gerais da cultura da macieira no estado de Aomori-Japão. Florianópolis: M. Machuca Meto, 1988. 90p.

MARQUES, P.M. et al. Crescimento, esporulação e viabilidade de fungos entomopatogênicos em meio contendo diferentes concentrações de óleo de Nim (Azadirachta indica). Ciência Rural, Santa Maria, v.34, n.6, p.1675-1680, 2004.

MOSSINI, S.A.G.; KEMMELMEIER, C. A árvore Nim (Azadirachta indica. A. Juss.): múltiplos usos. Acta Farmaceutica Bonaerense, Buenos Aires, v.24, n.1, p.139$148,2005$.
MOSSINI, S.A.G. et al. Inhibition of patulin production by Penicillium expansum cultured whith Neem (Azadirachta indica) Leaf Extracts. Journal of Basic Microbiology, Weinheim, v.44, p.106-113, 2004.

PITT, J.I.; HOCKING, A.D. Fungi and food spoilage. London: Blackie Academic \& Professional, 1997. 593p.

PRIETA, J. et al. Determination of patulin by diphasic dialysis extraction and thin layer chromatography. Journal of Food Protection, Ames, v.55, n.2, p.1001-1002, 1992.

RAZZAGHI-ABYANEH, M. et al. Morphological alterations in toxigenic Aspergillus parasiticus exposed to neem (Azadirachta indica) leaf and seed aqueous extracts. Mycophatologia, Dordrecht, v.159, p.565-570, 2005.

ROSS, G. Patulina: parâmetros que influem na produção, detoxicação e considerações sobre microbiota fúngica em maçã (Malus domestica B.). 1995. 108f. Dissertação (Mestrado em ciência de Alimentos) - Curso de Pós-graduação em Ciência de Alimentos, Universidade Estadual de Londrina.

SCOTT, P.M.; KENNEDY, B.P.C. Improved method for thin layer chromatographic determination of patulin in apple juice. Journal of the Association of Official Analytical Chemists, Arlington, v.56, n.4, p.813-816, 1973.

SINHA, K.K.; BHATNAGAR, D. Mycotoxins in agriculture and food dafety. New York: Marcel Dekker, 1998. 511p.

SMITH, D.; ONIONS, A.G.H. The preservation and maintenance of living fungi. Great Britain: Commonwealth Mycologycal Institute, 1983. 51p.

TANIWAKI, M.H. et al. Bolores produtores de patulina em maçã e suco industrializados. Coletânea do Instituto de Tecnologia de Alimentos, Campinas, v.19, n.1, p.42-49, 1989.

TEIXEIRA, A.V.G. et al. Obtenção e purificação de Patulina produzida por Penicillium sp isolados de maçã (Malus domestica B). In: ENCONTRO NACIONAL DE MICOTOXINAS, 9., 1998, Florianópolis, SC. Anais... Florianópolis: Universidade Estadual de Santa Catarina, Centro de Ciências Agrárias, 1998. 175p. p.109. 